\title{
PERSPECTIVAS E PRÁTICAS DO MUSEU DO PATRIMÔNIO VIVO DE JOÃO PESSOA
}

Moysés Marcionilo de Siqueira Neto ${ }^{1}$

Laetitia Valadares Jourdan ${ }^{2}$

\section{Resumo}

O artigo apresenta as perspectivas e práticas do Museu do Patrimônio Vivo de João Pessoa. Para isso, analisa o processo museológico que atua na região da Grande João Pessoa, Estado da Paraíba, Brasil. O museu tem como missão o desenvolvimento comunitário através da proposição de ações de salvaguarda para o patrimônio imaterial conjuntamente com jovens das comunidades envolvidas. O artigo explora as inovações conceituais que possibilitaram a criação de um museu sem paredes, localizado em lugares representativos das atividades culturais - como a casa de mestres e agentes culturais, lugares de trabalho, festas, celebrações e brincadeiras - e ao entender-se como ambiente dinâmico, de

1 É graduado em História pela Universidade Federal de Pernambuco e tem mestrado em Memória Social e Patrimônio Cultural pela Universidade Federal de Pelotas. Atuou como consultor da Unesco/IPHAN. Foi professor substituto do Núcleo de Arqueologia da Universidade Federal de Sergipe. Realizou o Curso de Estudos Avançados em Museologia (CEAM), da Universidade Lusófona de Lisboa/Associação Brasileira de Museologia. moyses neto@yahoo.com.br

2 É bacharel em Ciências Sociais pela UFMG e mestre em Antropologia aplicada ao desenvolvimento sustentável pela Université de Provence. Desde 2009 desenvole pesquisas em torno dos temas do patrimônio imaterial e do desenvolvimento sustentável. É uma das idealizadoras do projeto Museu do Patrimônio Vivo da Grande João Pessoa. 
construção conjunta, promovendo a conexão entre atores culturais de diferentes comunidades.

Palavras-chaves

Museu; processo museológico; Patrimônio Cultural Imaterial; João Pessoa.

\section{Abstract}

The article presents the perspectives and pratices of Museu do Patrimônio Vivo de João Pessoa. For this, analyzes the museological process that operates in the Greater João Pessoa, Paraíba, Brazil. The museum's mission is community development by proposing actions to safeguard intangible heritage together with young people from the communities involved. The article explores the conceptual innovations that made possible the creation of a museum without walls, located in representative places of cultural activities - such as home cultural masters and agents, work places, parties, celebrations and games - and to be construed as environment dynamic, joint construction, promoting the connection between cultural actors from different communities.

\section{Keywords}

Museum; museological process; Intangible Cultural Heritage; João Pessoa.

\section{UM MUSEU PARA O PATRIMÔNIO IMATERIAL}

No Brasil, desde 1937, o patrimônio institucionalizado foi traduzido pelo instrumento do tombamento e controlado pelo Serviço do Patrimônio Histórico e Artístico Nacional- SPHAN -, atual Instituto do Patrimônio Histórico e Artístico Nacional - IPHAN. O discurso técnico da arquitetura e do restauro e de uma história política oficial, auxiliados por uma retórica da perda, foram as 
narrativas principais nos discursos das políticas de preservação. A atuação da política federal de patrimônio resultou na criação de uma imagem do Estado Nacional como branca, católica e elitista através da seleção de seus ditos patrimônios históricos e artísticos distribuídos nos livros de tombo (ARANTES, 2001; FONSECA, 1997; GONÇALVES, 2002; VELHO, 2006).

As imagens da identidade nacional alteraram radicalmente com o processo de reabertura política no Brasil, nos anos 1980, devido principalmente a participação efetivas das minorias na formulação de políticas públicas e legislações, que culminou na Constituição de 1988, em seus artigos 215 e 216 . Assim, encontra-se a ideia de que as formulações estatais no campo do patrimônio são dinâmicas, atendendo aos contextos específicos em seus diálogos e conflitos com a sociedade e os grupos sociais envolvidos.

Com influências e demandas oriundas de movimentos, convenções e documentos internacionais, muitos orientados pela Unesco, e nacionais, mobilizados principalmente pelo IPHAN, a ideia de Patrimônio Imaterial tomou força, entre as décadas de 1980 e 1990, para atualizar as noção e políticas de patrimônio e, assim, suprir as reivindicações de minorias étnicas e sociais deflagradas durante o período. Mudanças, em menor ou maior grau, então, ocorreram nas distintas dimensões do patrimônio: nos conceitos, nas políticas, nas legislações, nas técnicas, nas questões econômicas... Tais anseios e mudanças nas noções de cultura, do passado nacional, do patrimônio cultural por concepções mais amplas e democráticas - consequentemente políticas publicas e instrumentos de preservação - resultaram no pioneiro Decreto 3.551/2000. O decreto instituiu o Registro de Bens Culturais de Natureza Imaterial e cria o Programa Nacional do Patrimônio Cultural.

A criação do Decreto-lei 3.551/2000, e, dentro do IPHAN, do Departamento do Patrimônio Imaterial - DPI -, apresentam-se como marcos nas estratégias legítimas da construção de uma nova política de patrimônio. Essas políticas ganharam força no governo Lula (2002-2010), com o fomento do Programa Nacional do 
Patrimônio Imaterial (PNPI), que promove o inventário, a salvaguarda e o registro de referências culturais do país. Intenta-se dar vazão às novas vozes sociais e suas narrativas diversas, forjando patrimônios nos múltiplos suportes em que está ancorada a diversidade brasileira. Para isso, as novas políticas (Programa Nacional do Patrimônio Imaterial), saberes (Antropologia, História Cultural...) e métodos (INRC) foram articulados para tal feito. (GONÇALVES, 2003; FONSECA, 2003).

Falar de patrimônio imaterial, então, longe da simples dicotomia material/imaterial, refere-se aos saberes e heranças coletivas que um determinado grupo compartilha e deseja preservar, salvaguardar, proteger e difundir. Esses bens, baseados em um determinado sistema de linguagem e expressão, são transmitidos por via da oralidade, da vivência ou da escrita, de forma a se manter vivo, transformando-se através das gerações. Eles têm como principal característica seu caráter dinâmico. São práticas, expressões, conhecimentos e modos de fazer, assim como os materiais e lugares associados a essas atividades, que ganham o status de patrimônio não por seu produto final, mas pelo significado que portam para a formação identitária de um grupo.

Se por um lado tal dinamismo garante que esses bens respondam à necessidade de um sentimento de identidade e continuidade dos grupos deles detentores, ele também traz a esses bens certa fragilidade no contexto atual, em que as mudanças são numerosas e rápidas. Apesar de estarem ligados a patrimônios materiais, a dinâmica dos bens imateriais exige meios de ação diferenciados e uma forma de promoção específica.

Como outras cidades do Brasil, João Pessoa, a capital do Estado da Paraíba, é espaço das ações de diferentes grupos sociais e suas formas de produzir e partilhar cultura. A cidade possui uma forte efervescência cultural, sobretudo no que diz respeito à cultura dita popular e tradicional, atualmente entendidos como parte do patrimônio nacional sob a guarda conceitual e institucional do patrimônio imaterial. Em cada bairro, principalmente nos mais populares, podemos encontrar uma infinidade de manifestações 
culturais importantes.

A riqueza cultural contrasta com as carências de infraestrutura social: são diferentes grupos e atores, com diversas expressões culturais que se espalham por vários bairros da cidade, muitas vezes considerados como áreas de risco, com um grau de pobreza importante e um alto índice de violência. As representações regularmente projetadas pelas mídias televisivas e impressas apenas observam as comunidade como local de violência e pobreza, frequentemente oferecendo riscos às demais áreas consideradas nobres da cidade.

As políticas culturais locais ainda não dão conta de atender a essa vasta demanda. É possível observar que a situação das comunidades portadoras das denominadas "cultura popular" ou "tradicional" é muitas vezes marcada por uma condição de falta, que denuncia a realidade de exclusão social e econômica vivida por esses grupos. A partir dessas dificuldades é possível formular algumas demandas identificadas nos discursos de integrantes desses grupos, como o desejo de uma maior valorização da cultura popular, sobretudo entre as novas gerações; a necessidade de garantia dos meios para a transmissão desses saberes, como o acesso às matérias-primas; a importância do reconhecimento dessas expressões culturais pelas autoridades locais, assim como da garantia de acesso às políticas públicas; o valor das trocas entre os grupos e comunidades portadoras desses bens; e a vontade de uma inserção no mundo globalizado, não só para a divulgação desses bens, mas também para a garantia do respeito de seus direitos. Percebe-se que tais demandas são intimamente ligadas ao caráter marginal dessas comunidades e de suas expressões culturais. A busca pela salvaguarda desses patrimônios teria como caminho possível a inserção desses grupos e de suas atividades no atual contexto econômico e social.

A cultura pode, então, ser meio de inclusão e formação de sujeitos. Nesse sentido ela pode ser vista como uma resposta à ideia que define o desenvolvimento como uma maquinaria de dominação pela qual os saberes locais são desvalorizados e a heterogeneidade 
cultural não é levada em conta (ESCOBAR, 1997). A ideia de um processo museológico apareceu como fundamental para a proteção e promoção de um bem imaterial, se constituindo como o trabalho com seus significados e/ou processos de resignificações.

Além de um espaço de exposição de objetos, escolhidos por uma elite intelectual e visando um público restrito e não participativo, as propostas contemporâneas de museus apontam para a criação de um espaço social de encontro em torno do conhecimento das próprias questões contextuais desses patrimônios imateriais. O museu pode ser visto como um gerador de novos sentido para a população local, fortalecendo o processo de formação identitária e promovendo a melhoria da qualidade de vida dos grupos sociais que habitam a região. Através dele, as dimensões simbólica, cidadã e econômica da cultura poderiam ser trabalhadas na elaboração de um planos de desenvolvimento comunitário e de salvaguarda dos bens, tendo os próprios moradores e executantes das manifestações culturais como agentes dessa mobilização.

\section{O MUSEU DO PATRIMÔNIO VIVO DA GRANDE JOÃO PESSOA}

Foi através das novas possibilidades de se construir museus e processos museológicos que surgiu a ideia de criar o projeto do Museu do Patrimônio Vivo da Grande João Pessoa, desenvolvido pelo Coletivo Jaraguá,desde 2012 na capital paraibana. O Projeto foi financiado no seu primeiro ano (2012-2013) pelo Fundo Municipal de Cultura (FMC). No segundo ano (2013-2014), o financiamento foi realizado pelo Fundo de Incentivo à Cultura do Governo do Estado da Paraíba (FIC).

O Museu do Patrimônio Vivo de João Pessoa percebeu a cidade de João Pessoa e, em sua segunda fase, os municípios de Lucena, Cabedelo, João Pessoa, Santa Rita e Conde como um espaço repleto que patrimônios vivos. O museu reconhece a grande riqueza cultural de cada comunidade dentro das cidades e procura responder às diferentes questões que a salvaguarda do patrimônio 
imaterial coloca, levando em consideração sua singularidade e sua dinamicidade. Além disso, o Museu do Patrimônio Vivo da Grande João Pessoa tem ainda a intenção de constituir uma alternativa de desenvolvimento para as regiões e grupos portadores desses bens culturais.

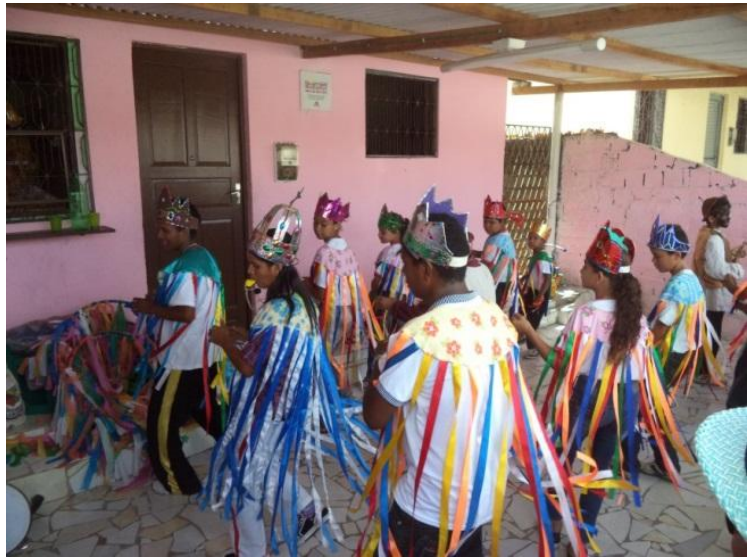

Imagem 1 - Expressão cultural Cavalo Marinho Infantíl Semenes do Mestre João do Boi - Comunidade do Novais, Município de João Pessoa, Paraíba. Foto: Angela Carneiro

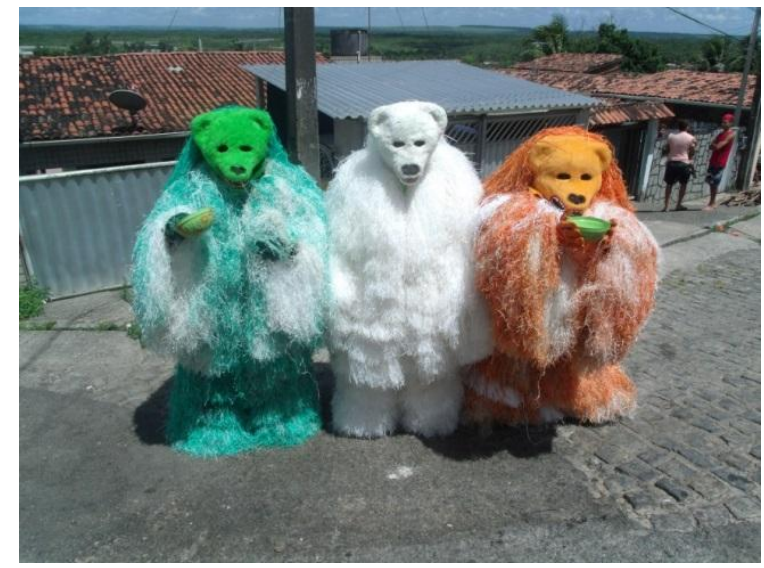

Imagem 2 - Forma de expressão da La Ursa, comunidade do Roger, Municipio de João Pessoa, Paraíba.

Foto: Nina Nascimento 
Um dos objetivos do museu é ser um espaço de formação, de debate, de troca e de melhoria das condições sociais e econômicas das comunidades participantes. Baseado na ideia de que as expressões culturais são um importante fator de desenvolvimento, o museu foi elaborado tentando atender às demandas identificadas no discurso de lideranças culturais de grupos locais. Seja a respeito da falta de interesse dos jovens em se envolver com a cultura popular e em valorizá-la; seja a insatisfação com relação à falta de registro das atividades culturais e de produtos de divulgação; assim como da dificuldade de acesso às políticas públicas culturais. Essa última queixa é relacionada, entre outras coisas, à distância imposta pela linguagem técnica e burocrática exigida por grande parte dos editais, em um meio onde o analfabetismo é uma realidade muito presente.

A partir do reconhecimento e respeito dos saberes das comunidades tradicionais, do incentivo à participação política e de promoção do acesso às políticas públicas - pressupostos básicos do exercício da verdadeira cidadania -, e de uma relação educativa baseada no diálogo, o Museu do Patrimônio Vivo da Grande João Pessoa se apresenta como um meio de real utilidade social, uma vez que promove a autonomia, o protagonismo e a visibilidade de manifestações culturais e comunidades muitas vezes pouco reconhecidas e valorizadas.

Sendo uma construção conjunta com organizações e agentes culturais das comunidades, o projeto entra em consonância com os princípios da museologia dita social e comunitária. Em ambos o museu não tem mais como principal objetivo conservar e exibir objetos a um público, mas passa a ser uma instituição dirigida a sujeitos sociais, onde a conservação só adquire sentido através de uma inserção no desenvolvimento econômico e social. Nesse contexto, o Museu do Patrimônio Vivo da Grande João Pessoa busca ser um instrumento dinâmico de educação popular, divulgação cultural e preservação de identidades. Seu desejo é a apropriação coletiva do saber, da produção cultural e do conhecimento local pelos atores sociais que os produzem. É essa autogestão que lhe dá 
legitimidade diante das comunidades e frente às diferentes instituições. Dentro desse contexto o Museu do Patrimônio Vivo está sempre em construção. Sua definição, seus objetivos e seu acervo são uma criação conjunta e contínua, feita entre agentes, coordenação e comunidade. Assim, um dos exercícios feitos junto aos agentes foi justamente o de definir do quê é - e o quê eles querem que seja - esse Museu.

A partir desse trabalho conjunto de diálogo, durante a oficina de educação patrimonial do segundo ano do projeto, o grupo de agentes construiu a seguinte definição:

"O Museu do Patrimônio Vivo é um processo museológico que, através de um projeto, cria um espaço de troca de histórias, culturas, sonhos, sentimentos e memórias. É espaço de pesquisa, interpretação e exposição com fins de salvaguarda para reconhecer, valorizar, preservar e dar visibilidade aos bens imateriais. Esse processo acontece a partir dos agentes comunitários, com a participação da comunidade, buscando contribuir com o desenvolvimento educacional, cultural e socioeconômico."

Baseados nessa conceituação, observamos a apropriação do Projeto por parte dos agentes, uma vez que a proposta inicial é justamente o de construir um centro de gestão cultural onde os distintos atores sociais se encontram em torno de valores comuns, se configurando por um espaço de trocas na busca por ações de renovações desejadas pelos grupos participantes ali representados. É um local sem delimitações fixas, sem paredes, um espaço social onde decisões são tomadas para o planejamento e a realização de projetos referentes às origens e ao desenvolvimento das comunidades que dele fazem parte.

Fazendo uma analogia com o museu dito "tradicional", imagine que: os nossos muros e paredes - que comporiam o edifício do museu - são a própria cidade, ampliando ou reduzindo à medida que o processo deseja; o que seriam as salas são, para nós, as 15 localidades selecionadas; nosso acervo são as forma de expressão, 
celebrações, lugares e ofícios que são bens culturais de cada localidade; nossos curadores - com o trabalho de seleção, pesquisa e preservação desse acervo - são os próprios agentes culturais moradores das localidades; nossos educadores, os praticantes desses bens culturais; o site, o catálogo e a exposição itinerante são as narrativas e imagens que comunicam e conectam esse rico acervo vivo e dinâmico que a Grande João Pessoa possui; o nosso dia e horário de funcionamento, longe de uma escala administrativa, obedece ao calendário de cada referência cultural.

\section{FORMAÇÃO DOS AGENTES CULTURAIS}

O Museu tem como principal atividade a formação de Agentes Culturais Comunitários. São jovens entre 15 e 29 anos moradores de comunidades da Grande João Pessoa, que, embora ricas em patrimônios culturais imateriais, vivem em uma realidade social precária, apresentando baixos índices de qualidade de vida e um número muito elevado de analfabetismo. O processo de seleção desses jovens foi feito em parceria com instituições locais e lideranças culturais comunitárias tidas como referências da cultura popular de cada bairro, garantindo assim uma legitimidade desses agentes diante de suas comunidades. Mestres, antigos moradores e participantes da vida cultural de cada localidade indicaram jovens que poderiam representar a comunidade e a cultura local dentro do projeto.

A formação dos agentes comunitários se deu através de oficinas que ocorreram durante duas tardes da semana. Foram oficinas de informática, língua portuguesa, direito cultural, educação patrimonial, elaboração de projetos, economia da cultura, sistematização de dados e fotografia. Essas oficinas, para além de ambicionar a valorização da cultura local, buscam dar bases para que esses jovens possam responder a editais, redigir releases, acompanhar e assessorar a divulgação e a produção de eventos culturais, assim como representar e defender os direitos de suas comunidades. Hoje, podemos citar o exemplo de uma das agentes 
participantes do Projeto que atualmente é presidente da Associação de Mulheres do Porto do Capim, coletivo que busca melhorias na comunidade e a defesa de seus direitos.

A oficina de informática, por exemplo, tem como objetivo não apenas dar noções sobre programas, mas também ensinar a utilização da internet como instrumento de pesquisa, construção e alimentação do site do Museu, que deve ser gerido pelos próprios agentes. A oficina de língua portuguesa, por sua vez, tenta suprir uma falha existente no nosso sistema de ensino convencional, buscando aprimorar a capacidade de argumentação e de interpretação, bem como a gramática dos jovens participantes do Projeto. Para tanto, essa oficina trabalha em estreita relação com a oficina de elaboração de projetos. Ambas dão suporte a um dos produtos finais dos agentes: o plano de salvaguarda de um bem cultural local.

O plano de salvaguarda também é baseado no conteúdo passado através das oficinas de direito cultural e economia da cultura. Assim, a elaboração de um projeto de ação ao final da formação é uma forma de colocar em prática o conteúdo trabalhado durante as aulas. Podemos destacar o exemplo de uma agente do bairro do Roger que, ao final do primeiro ano de formação no Museu, teve seu projeto aprovado no edital de oficinas culturais nos bairros, realizado pela Fundação de Cultura de João Pessoa, o Funjope, órgão responsável pela cultura no âmbito municipal.

A oficina de fotografia, por outro lado, reconhece a importância do registro em imagem. Através dessa oficina os agentes aprendem noções da técnica fotográfica, assim como seu valor em uma pesquisa. É a partir desse trabalho que esses jovens irão construir o acervo iconográfico do Museu, que será disponibilizado no site. É também a partir dessa oficina que são realizadas as imagens que irão compor a exposição fotográfica itinerante, que visita cada localidade participante do projeto, apresentando os resultados das pesquisas realizadas de forma imagética.

Por fim, a oficina de educação patrimonial serve como uma 
base sobre a qual todas as outras oficinas se constroem. Ela auxilia na construção de novos olhares dos agentes sobre o patrimônio cultural, criando questionamentos, indagações, contextualizando as problemáticas dentro da perspectiva do patrimônio e da construção identitária. É essa oficina que busca dar as ferramentas necessárias para a escolha dos bens culturais, trabalhando conceitos tais como referência, representatividade e identidade, fornecendo as bases metodológicas para os trabalhos de campo.

\section{PESQUISA NAS COMUNIDADES}

Ao longo de toda a formação os agentes culturais do museu fazem um trabalho de levantamento e pesquisa sobre os bairros onde vivem e sobre os bens culturais identificados por eles nessas localidades, de forma a compor o acervo vivo do Museu. Tal acervo é composto por pessoas, lugares, narrativas, calendários festivos e expressões culturais de um modo geral. A pesquisa se baseia em dados secundários, obtidos através de pesquisas nas prefeituras, postos de saúde, livros, revistas e acervos privados, entre outros. Para os dados primários os agentes se utilizam de entrevistas e da metodologia de observação participante, através da qual eles têm oportunidade de analisar e vivenciar seus objetos de pesquisa.

Tendo em vista a íntima relação do patrimônio imaterial com o lugar onde este é vivido, o Museu do Patrimônio Vivo da Grande João Pessoa tem como locação os espaços representativos das atividades culturais, como a casa dos mestres e dos atores culturais das comunidades, além dos lugares de trabalho, das festas, das celebrações e das brincadeiras populares. Além disso, prédios históricos e paisagens naturais fazem parte desse quadro. O Museu é, assim, representado por um mapa das expressões e lugares culturais da Grande João Pessoa, ilustrando uma rede de pessoas, locais e objetos de grande referência para as localidades envolvidas. É interessante observar que ao criar um espaço de troca e de encontro entre jovens de diferentes bairros, o Museu fortalece essa rede. Muitas vezes identificamos uma mesma expressão ou bem 
cultural em diferentes locais, realizados por pessoas que não se conhecem, nunca se viram. Nesse momento de encontro, histórias, conhecimentos e experiências são compartilhados.

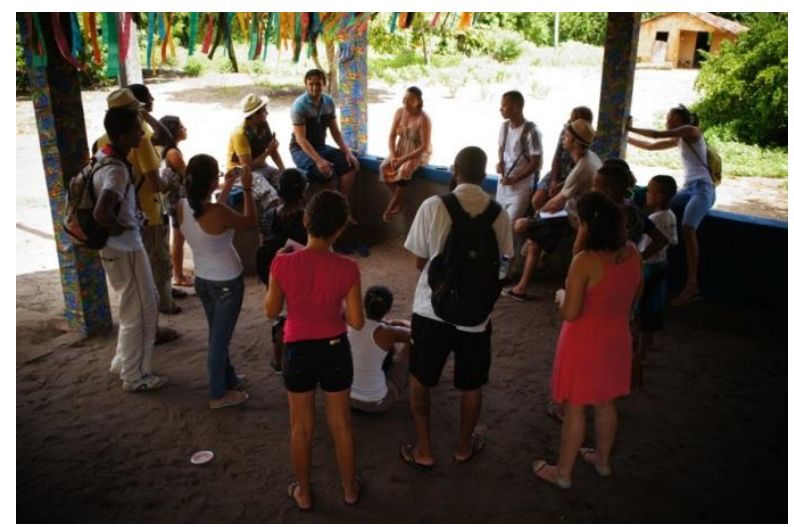

Imagem 3- Agentes culturais durante entrevista com Dona Lenita, Mestra da expressão cultural Coco de Roda Novo Quilombo - comunidade Gurugi/Ipiranga, município do Conde, Paraíba. Foto: Moysés Siqueira.

Para que essa troca seja ainda mais rica, o Museu prevê visitas de campo em grupo. Desse modo, para além das oficinas, durante o segundo ciclo do projeto, os sábados são reservados a verdadeiras excursões, organizadas pelos agentes culturais representantes da localidade a ser visitada. Os agentes devem assim montar um roteiro, com lugares a serem vistos e pessoas a serem visitadas. Durante esse trabalho o agente expõe as riquezas de sua comunidade e a importância que cada uma daquelas referências culturais possui para a formação da identidade daquele grupo. É interessante perceber que esse exercício permite aos demais agentes conhecer e vivenciar lugares e culturas diferentes, expandindo sua compreensão sobre a diversidade cultural da Grande João Pessoa e da Paraíba como um todo.

Como já foi anteriormente dito, a identificação e a pesquisa dos diversos bens presentes nessas comunidades é totalmente realizada pelos jovens agentes a partir de dados secundários, idas a 
campo e entrevistas. Com base nos dados coletados as escolhas dos bens a serem aprofundados é discutida em grupo com a equipe de coordenação e os monitores das oficinas. Os jovens devem nesse momento justificar suas escolhas, mostrando a pertinência e a importância daqueles bens para sua localidade, assim como a necessidade de um registro. Uma vez definidos os bens, os agentes preenchem as fichas, desenvolvidas a partir da metodologia utilizada pelo Inventário Nacional das Referências Culturais INRC/IPHAN. São quatro tipos de fichas : a ficha de localidade, a de mapeamento dos bens, a ficha de levantamento documental (onde são listados livros, artigos, Cds, filmes e outros materiais já existentes que têm como tema o bem cultural ou a localidade) e a ficha de bens. Essa última é ainda subdividida em quatro tipos, segundo o bem escolhido: ofícios, lugares, formas de expressão e celebrações. Assim, além dos bens culturais, os agentes devem também pesquisar sua localidade, identificando problemas, potencialidades e levantando dados quantitativos e qualitativos com relação às condições de vida do lugar onde moram. Essa pesquisa é fundamental para localizar o bem cultural dentro de seu contexto.

Apesar de ter como base a metodologia do INRC, a pesquisa desenvolvida pelos jovens não se propõe como um estudo exaustivo da cultura popular e do patrimônio imaterial dessas localidades. 0 objetivo dessas pesquisas é, sobretudo, o conhecimento e a valorização dessa cultura no seio das comunidades, assim como a identificação das expressões culturais que o próprio grupo estabelece como representativo de sua identidade. Para tanto, alguns pontos importantes devem ser levantados durante essa pesquisa, tais como a estrutura da localidade - tanto no que diz respeito à sua geografia, quanto aos equipamentos públicos existentes; as pessoas tidas como referências culturais locais; o histórico do bairro; os principais bens culturais existentes, sejam eles materiais ou imateriais; a importância desses bens para a comunidade; e as principais dificuldades existentes para sua continuidade.

A passagem das entrevistas e informações adquiridas de 
diferentes formas durante o trabalho de campo para o formato das fichas ainda é um desafio. Isso se deve a diferentes razões, como por exemplo a dificuldade de se separar e categorizar dados que são obtidos dentro de um todo. Buscando atenuar esse problema, no segundo ano do Projeto foi elaborada a oficina de sistematização de dados, que teve como objetivo auxiliar o preenchimento das fichas, tentando reduzir a perda de informações. Essa experiência, embora rica e bem sucedida, se mostrou o início de um longo caminho a ser construído em conjunto com os agentes e demais atores do Museu, na busca de transpor para o papel uma história viva, repleta de cores, memórias, cheiros, sons, gestos e emoções.

Podemos aqui enumerar os produtos produzidos pelos agentes culturais formados pelo Projeto. São eles: as fichas sobre as localidades; um mapeamento dos bens culturais identificados; um levantamento de fontes secundárias; as fichas sobre os bens culturais imateriais pesquisados de forma aprofundada; um catálogo com o resultado das pesquisas; um projeto de salvaguarda para um dos bens identificados ; a exposição fotográfica ; e também um site, onde todo o material será disponibilizado, incluindo as datas festivas, de ensaios, os contatos de lideranças culturais e de grupos para apresentações, assim como fotos e roteiros de visita. Para além dessas atividades o Museu realizou dois seminários, que foram organizados pelos agentes junto à equipe técnica do Projeto. Os temas abordados foram a salvaguarda do patrimônio imaterial como forma de desenvolvimento sustentável de comunidades e a relação entre cultura popular e território. 


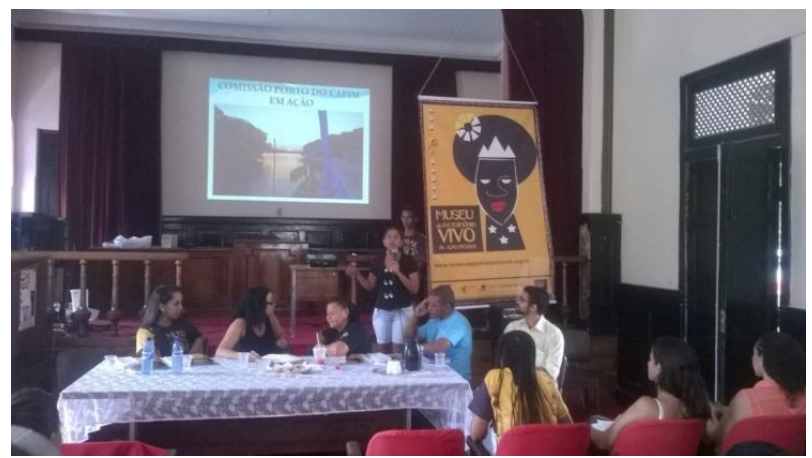

Imagem 4 - Seminário Cultura Popular e Território realizado pelos próprios agentes para troca de experiências entre as comunidades e instituições interessadas. Foto : Edson Silva

Dessa forma, o museu busca desenvolver a sustentabilidade das atividades culturais através da preparação de jovens para o mercado cultural e o contato com os mecanismos de salvaguarda do patrimônio imaterial. A proposta tem por intuito promover a igualdade de oportunidade de acesso à fruição de ações culturais e à formação para uma produção cultural autônoma por parte das comunidades envolvidas no Projeto. Ressalta-se que a criação de um museu através de um processo participativo que envolve representantes das comunidades contribui para uma maior visibilidade da cultura local, estimulando um processo interno de valorização, bem como seu reconhecimento pela população como um todo. Para além disso, é possível observar uma valorização do próprio agente dentro de sua comunidade, que se transforma em um importante ator de mediação. $O$ interesse pela cultura local por parte de atores externos através da remuneração de jovens moradores para pesquisas sobre esse tema questiona os mais curiosos sobre a importância desses bens e os leva a refletir sobre o papel da cultura na economia local.

\section{SALVAGUARDA DOS BENS IDENTIFICADOS}

O museu se caracteriza dessa forma como uma ação de salvaguarda como definido pelo Instituto do Patrimônio Histórico e 
Artístico Nacional (IPHAN), ou seja, como um conjunto de ações que contribui para o melhoramento das condições de produção, reprodução e transmissão de bens culturais imateriais.

Além disso, o Projeto segue as três premissas de um plano de salvaguarda: o respeito à íntima relação entre a reprodução e a continuidade dos bens culturais vivos e seus produtores e portadores - desse modo, estes devem sempre participar ativamente do processo de identificação, reconhecimento e apoio aos seus bens culturais -; em segundo lugar identificamos o caráter essencial da garantia das condições sociais e do meio ambiente necessárias para a produção, reprodução e transmissão desses bens; e por último, a importância do conhecimento do universo onde o patrimônio em questão é criado e estruturado. Para tanto, o Projeto não se limita a pesquisas sobre bens culturais, mas também sobre as próprias comunidades. Os agentes são assim levados a conhecer melhor seus bairros, desenvolvendo um olhar crítico sobre sua estrutura e seu papel dentro da Grande João Pessoa.

Essas três diretivas devem ter como fundamento, no entanto, a noção de que a continuidade e a valorização desses bens culturais só são possíveis a partir de sua inserção na sociedade moderna. Nesse sentido, as ações de salvaguarda não têm como objetivo evitar a interação entre as culturas ditas tradicionais e a modernidade - mesmo porque isso é impossível. Esses planos devem, por outro lado, buscar fornecer as condições propícias para que esse encontro se faça de maneira mais justa, permitindo o estabelecimento de trocas

Já que a valorização da cultura dita tradicional é condição indispensável para a promoção e a salvaguarda de bens culturais de natureza imaterial, a integração do conceito de diversidade da cultura através do mercado cultural se apresenta, no contexto atual de um mundo globalizado e capitalista, como um importante elemento de apoio à manutenção desses bens. É a partir dessa integração que essas culturas consideradas como em situação risco, poderão fazer frente à homogeneidade e à mercantilização impostas pelos meios de comunicação de massa. Isso é possível graças às 
especificidades que diferenciam a indústria cultural dos outros modelos industriais conhecidos. Nesse contexto os produtos são bens e serviços culturais, que não são considerados a partir do ponto de vista de sua utilidade ou de sua finalidade específica. Eles encarnam e transmitem expressões culturais, independentemente do valor comercial que eles possam ter.

Essa integração com o mercado cultural seria assim primordial para as etapas pelas quais os processos de salvaguarda e de reconhecimento devem passar. O reconhecimento, nesse contexto, se estabelece em diferentes níveis: a consciência da pessoa que vive em função de seu saber, de sua expressão cultural; a comunidade, que deve poder reconhecer suas práticas e suas tradições para se apropriar e as transmitir; e o nível dos Estados e das organizações internacionais, no qual se articulam as políticas e os instrumentos para promoção e preservação do patrimônio imaterial. A documentação, a ampliação dos espaços institucionais de salvaguarda e a defesa dos direitos de imagem e de propriedade intelectual coletiva se apresentam como ações fundamentais nessa etapa, para o reconhecimento da importância de um patrimônio cultural local no plano nacional e/ou mundial. As oficinas propostas pelo Museu buscam, dessa maneira, garantir o acesso às ferramentas necessárias para a participação ativa dessas comunidades dentro desse movimento. Todavia, as questões relativas aos direitos intelectuais e do autor, bem como os direitos de imagem, são ainda um obstáculo quando tratamos de expressões culturais imateriais. Tais direitos são fundamentos da indústria cultural, porém eles não correspondem à lógica comunitária dos grupos.

Mesmo que mecanismos de políticas de salvaguarda citem a importância de assegurar os direitos intelectuais individuais e coletivos dos grupos portadores de um bem imaterial, ainda resta um longo caminho a percorrer para que as legislações consigam representar a realidade dessas comunidades. Nesse sentido, o Museu do Patrimônio Vivo busca fornecer aos jovens agentes culturais os instrumentos para pensarem a questão, buscando a 
melhor forma de defenderem seus direitos, dentro do contexto atual.

\section{EXPOSIÇÕES NAS COMUNIDADES E NA WEB}

As informações das pesquisas, fotografias, bem como as narrativas produzidas pelos agentes culturais foram transformadas em uma exposição itinerante e em um website (www.museudopatrimoniovivo.com). A participação dos agentes foi o eixo central da produção das representações sobre as manifestações dos grupos culturais e suas comunidades. Para web, foi montada uma plataforma que divulgasse os conteúdos produzidos por eles, além da possibilidade de atualização de informações e, principalmente, uma agenda cultural das comunidades.

A exposição itinerante circulou nas comunidades envolvidas na primeira fase do projeto, com participação direta dos grupos culturais envolvidos, seja na seleção do local a ser instalada, montagem, guarda da exposição e serviços educativos. A exposição itinerante também foi montada em locais mais tradicionais, como a Faculdade de Direito da Universidade Federal da Paraíba, durante o seminário produzido pelo Museu para debater questões de território e cultura com líderes das comunidades envolvidas.

No primeiro nível, a exposição trabalhou com as ideias de territorizalização das referências culturais trabalhadas pelos agentes culturais. A ideia de território foi propositalmente selecionada para politizar as questões pelos quais essas referências culturais tem passado, além de servir como importante suporte das lutas sociais locais de cada grupo e suas comunidades. A ideia de território foi envolvida em textos e imagens que proporcionaram aos visitantes um interessante jogo temporal: o passado, o presente e o futuro das comunidades. As linguagens foram simplificadas e cuidadosamente postas em dialogo as cores e imagens pensadas para exposição.

Os recursos expográficos selecionados foram o mais móveis 
possíveis, simplificando o processo de locomoção, bem como de guarda e conservação desse material. As técnicas utilizadas concretizaram as ideias, conceitos e informações sobre o objetivo e missão do museu. As fotografias e textos proporcionaram um processo de forte identificação nas comunidades, pois as imagens foram produzidas por moradores do local: a dimensão do sentimento esteve em toda parte com o museu. Um varal com suportes para fotografias diversas deixou a exposição com um carater de obra aberta à participação local. Cada um podia fazer sua contribuição, deixando algo de suas memórias e histórias em cada uma das comunidades. Isso potencializou o conjunto de vivências pessoais que possibilitaram uma maior tradução das informações debatidas e envolvimento ainda maior de cada visitante. Um catálogo registrou as informações das pesquisas, bem como auxiliou no entendimento da exposição.

\section{PARA PENSAR O MUSEU DO PATRIMÔNIO VIVO DE JOÃO PESSOA}

Cocos de roda, lapinhas, capoeiras, maculelês, rezadeiras, pescadores, parteiras, igrejas, terreiros, quadrilhas, procissões, ala ursas, escolas de samba, cambindas, lendas, quadrilhas, entre muitas outras referências culturais, encantam os mais diversos espaços da Grande João Pessoa. Elas formam lugares que juntos transformam as cidades em um mosaico cultural vivo, dinâmico e colorido, bem diferente do simples mapa geopolítico que estudamos na escola. Em cada comunidade, encontramos os grandes heróis, que não tem os nomes gravados nas principais avenidas da cidade ou livros de História, mas são igualmente importantes, vivendo e defendendo a nossa cultura e suas expressões - passadas de geração em geração. Juntas, as manifestações culturais formam também um calendário bem diferente: acrescentam datas importantes na divisão do nosso tempo, na comemoração do viver em cada comunidade.

É interessante pensar o projeto de se criar um museu voltado 
e gerido justamente por agentes desses grupos que antes não ousavam nem mesmo ultrapassar as portas dos prédios dos museus considerados "sagrados", representantes do saber dito tradicional e instrumentos tradicionalmente ligados à certa elite minoritária. $\mathrm{O}$ projeto do Museu do Patrimônio Vivo da Grande João Pessoa se caracteriza, sobretudo, como uma busca de democratização desses espaços de poder através do empoderamento de grupos antes estigmatizados por uma história de exclusão. A realização das formações, pesquisas, exposições, website colaborativos e seminários são uma concretização dessa tomada de espaço, quando a discussão vai para além do campo das ideias, trazendo para o centro do debate os próprios atores envolvidos com suas vivências e tendo como mediadores e organizadores representantes dessas realidades múltiplas.

As experiências de gestão comunitária do museu têm como principal valor o fato de que cabe aos próprios grupos representados dizerem quem foram, quem são e quem desejam ser. A autodeterminação, tão em voga nos dias atuais com as questões indígenas e quilombolas, é aqui posta em prática, a partir de uma reconstrução do passado, uma resignificação do presente e a consciência de poder sobre o futuro. O processo de representação passa assim a seguir um sentido contrário. Se antes os objetos representados se adaptavam a uma ideia preconcebida, estabelecida por atores externos, nesse novo contexto o espaço do museu ganha maleabilidade e começa a se adaptar aos desejos e necessidades dos grupos comunitários, seus objetos, expressões e histórias ali representados.

Tal caráter de adaptação deve ser ainda maior quando tratamos de bens como os patrimônios imateriais, que possuem como característica fundamental a dinamicidade. Essa é ainda uma grande dificuldade enfrentada pelas políticas públicas voltadas para esses bens, uma vez que tais medidas visam universalizar princípios, se confrontando diariamente com a singularidade presente nas expressões culturais. Assim, percebemos que as ações colocadas em práticas por agentes externos, como o Estado, que se servem de 
instrumentos legais e burocráticos que não são necessariamente reconhecidos pelos atores, encontram numerosos problemas. Da mesma maneira conflitos surgem logo que uma iniciativa que se quer democrática (como as políticas de democratização cultural, por exemplo) é ao mesmo tempo baseada sobre os princípios da burocracia e aplicada a uma realidade de desigualdade e exclusão. A interação entre essas distintas realidades tem como resultado uma diferença entre as ações previstas, a prática e os resultados observados.

Dessa maneira, o Museu do Patrimônio Vivo da Grande João Pessoa busca trabalhar como mediador dessas diferentes linguagens para que essa interação se faça de maneira mais justa e eficaz. Desse modo, ao mesmo tempo que o museu busca a inserção desses grupos e de suas expressões culturais no mundo globalizado, ele tem como objetivo colocar à disposição dos participantes os meios necessários para que eles possam enfrentar os efeitos perversos inerentes a essas mudanças, oferecendo ferramentas para que essas comunidades desempenhem um papel ativo durante tal processo. 0 objetivo não é assim de determinar os caminhos pelos quais as expressões culturais de natureza imaterial da Grande João Pessoa serão tratadas, mas de possibilitar a abertura de alternativas, a partir de um desenvolvimento sustentável baseado na democratização, na diversidade e no respeito sem, no entanto, ignorar a realidade e o contexto existente, ou seja, de um sistema capitalista, fundado sob a ideia de mercado e de dinheiro.

A longo prazo, podemos imaginar que o objetivo do projeto do Museu do Patrimônio Vivo da Grande João Pessoa é a autonomia dessas comunidades e o pleno gozo de seus direitos. Organizados, conscientes de seu valor e da importância de seus bens culturais e armados com as ferramentas burocráticas, institucionais e jurídicas necessárias, os grupos culturais comunitários poderão exercer sua cidadania e fazer frente às adversidades do mundo atual de forma mais justa. 